\title{
The culture and inheritance of Huizhou architecture: taking the design practice of INK Weiping tourism cultural street as an example
}

\author{
Peng Zhiming ${ }^{1}$, Yang Yang ${ }^{2}$, Xiao Hanyue ${ }^{3}$, Li Yunzhang ${ }^{3}$, and Bi Zhongsong ${ }^{1,3 *}$ \\ ${ }^{1 *}$ College of Architectural and Engineering \& Research Center of Huizhou Architecture, Huangshan University,245041 Huangshan, \\ China $^{3}$ \\ ${ }^{2}$ School of Architecture, University of Sheffield, Sheffield S10 2TN, UK \\ ${ }^{3}$ College of Architecture and Environment, Sichuan University,610065 Chengdu, China
}

\begin{abstract}
This article uses the design analysis and insights of the Weiping Tourism Cultural Street, which the author participated in and practice to discuss how Huizhou culture can be protected and inherited in tourism cultural projects. Through the planning of the buildings of the project and the site planning of the surrounding environment, the formation of public spaces such as traditional streets, traditional theaters, as well as the influence of Huizhou culture on the space and architectural style and details of the building, the article interprets in detail the application of Huizhou architectural design and its traditional cultural connotations in cultural tourism development projects. At the same time, the article also discusses and summarizes the problems encountered in the protection and inheritance of Huizhou culture in the design and development process of the project, which has an enlightening effect on the better integration of the current practice of new Huizhou architecture with the current social and economic environment.
\end{abstract}

\section{Research Background}

Huizhou culture, Dunhuang culture, and Tibetan culture are listed as China's three major regional cultures. As the birthplace of Huizhou culture, Huizhou has unique natural geography and humanistic environment, which has not only cultivated the society, economy, art, and technology with distinctive local characteristics but also affected the local physical and spatial environment and the social relations between people closely related to it. In Huizhou, there are such a series of traditional Huizhou traditional buildings scattered in no matter of large and small villages; at different times of the year, villagers also hold various traditional festivals with local Huizhou cultural charm. And activities, such as "Tai Wang Gong" (celebrate the local protector of Huizhou), "Tai She Gong" (commemorate the god of land), the dance of grass dragon, Mulian Opera, etc. Huizhou's buildings and village spaces have an inseparable and close relationship with the local people because of these collective interactions.

Since Deng Xiaoping's reform and opening up the country in 1978, many foreign-funded enterprises and private capital have brought about significant changes in the appearance of China's cities. As a demonstration point of reform and opening up, many new cities, such as Shenzhen, have developed from a small village to a modern city full of tall buildings. In rural areas, the government has also implemented reforms. Scientific and technological agricultural methods have liberated a large amount of agricultural productivity, promoting drastic urbanization, modernization of life, and a relatively comfortable income level. These rural surplus labor forces have also migrated to the country's new round of urban strategies to promote the development of industry and service industries. Taking Huangshan City as an example, the rural population has continued to decrease this year, while the urban population has increased. ${ }^{[1]}$ The older people stay in the villages working in agriculture, while young people move to the city for better job opportunities. This phenomenon has changed the proportion of the rural population structure. The rural area has been hollowed out. What is lost is the influence of the material and cultural environment of the next generation and the inheritance of intangible cultural heritage.

To protect Huizhou's culture and promote its inheritance and development, the Huangshan City Government has adopted a series of measures to increase the protection of ancient Huizhou buildings and villages as cultural carriers, such as the "Hundred Villages and Thousand Buildings" project. By the end of August 2012, the planning of 101 ancient villages has been completed, and the protection and utilization of 83 ancient villages and 1051 old houses have been implemented. ${ }^{[2]}$ In addition to the government's policy and other macrolevel planning, Huizhou villages are also actively participating in market operations, attracting social and private capitals to develop, protect, and promote rural tourism development. ${ }^{[3]}$ In the current traditional Huizhou

* Corresponding author: bzs@stu.scu.edu.cn 
area, traditional buildings and villages have formed a two-way pattern in which the government leads in protection and market investment for development. In academia, researches showed interests and dedications to traditional village culture protection and renewal, ${ }^{[4-6]}$ restoration and protection of ancient buildings, ${ }^{[7]}$ the inheritance of tangible and intangible Hui culture heritage, the creation of new Huizhou style architectural design techniques. $^{[8-9]}$ At the same time, it has also sparked intense discussions on whether tourism development has "prosperity" or "decline" for rural culture. ${ }^{[10-12]}$

As a practicing designer of Huizhou-style architecture, the author discovered through continuous practice and observation in daily life that the culture and inheritance of Hui-style architecture need to consider economic factors and the social environment. Simply treating buildings as cultural relics without intersections with local people's daily lives, this kind of culture is static and is for viewing, rather than blending into the times and being understood by people. With the rise of China's real estate market, many residential buildings have emerged as symbols of commodities and capital. The government's current primary efforts are put on protecting traditional Huizhou architecture; innovations in designs of contemporary Huizhou architecture are left as a commercial project in most of the cultural and tourism projects invested by private owners. Private sectors have an inestimable role in promoting the culture and inheritance of Huizhou architecture's development. The entrusted Chinese independent architects thus also played a crucial role in the process. They need to ensure the interests of commercial capital and promote the expression of culture and art through their building design and further balance the two. The construction of Huizhou's traditional material and cultural environment, the elements, and the modern expression of traditional craftsmanship are conducive to evoking genius loci ${ }^{[13]}$ rooted in the site. At the same time, through local cultural interpretation and experience in tourism projects, it can be better for local people as well as visitors to have a deeper understanding and recognition of the traditionally inherited customs, ethics, and morals behind the architecture that constructs the cultural space of Huizhou. ${ }^{[14]}$ This article combines the design process of the INK Weiping Tourism Cultural Street that the author participated in as an example and used the architect's perspective to show how Huizhou's traditional culture is expressed in the design of the new Hui-style architecture through a comprehensive analysis. Additionally, the article will analyse how to better promote Huizhou culture's inheritance and development through cultural tourism projects from design practice experiences.

\section{Project introduction}

The project is located in Weiping Town, Chun'an County, Zhejiang Province, west of Beihong Bridge Head (Figure 1). The west side of the plot is Weiping Plaza (Figure 2), the south side is Xin'an River Reservoir, the east side is Hongqiao Street and commercial and residential buildings, and the north side is adjacent to Hubin Road.
The project is a comprehensive cultural tourism real estate project integrating cultural real estate, tourism real estate, and commercial real estate with the spiritual connotation of "inheriting Huizhou, creative reproduction, cultural platform." Old Weiping was initially affiliated with ancient Huizhou. Due to the Xin'an River water transport connected to the Huizhou area, the Huizhou culture was much influenced. The project aims to regenerate the historical and cultural district of old Weiping and brings back traditionally collective living sceneries and connections between people. By setting up cultural activities provided by the spatial design as a platform, local people and visitors can better understand and inherit the lost local living and endangered local culture.

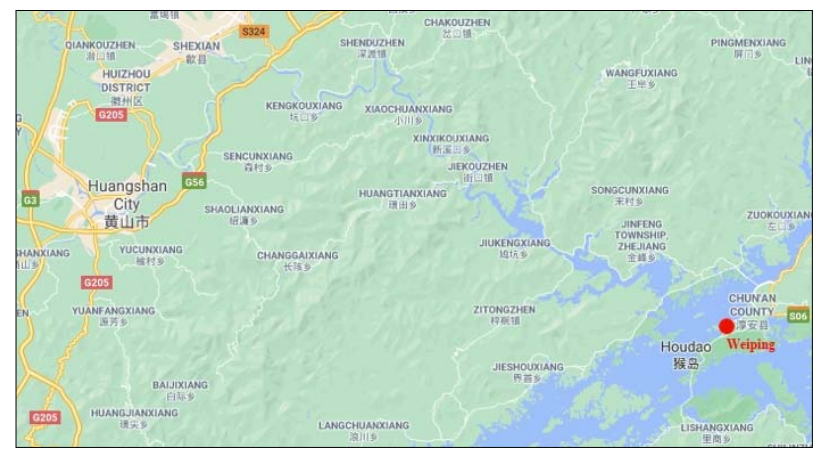

Fig. 1. The location of the project. Sources from the author.

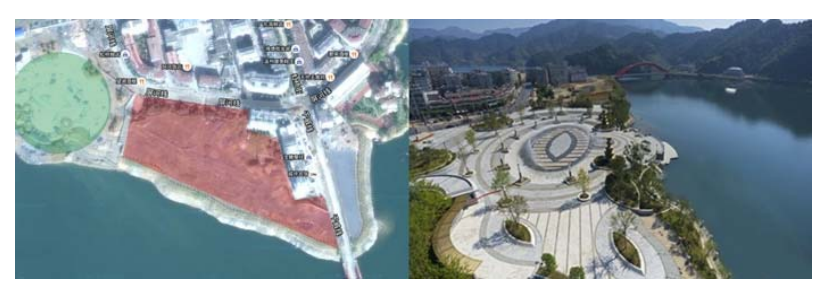

Fig. 2. Left: site plan(red) and Weiping Plaza (green). Right: Weiping Plaza. Sources from the author.

\section{Planning content and layout}

The project is divided into four functional areas: entrance area, Weiping old street area, artist club area, and lakeside landscape area (Figure 3).

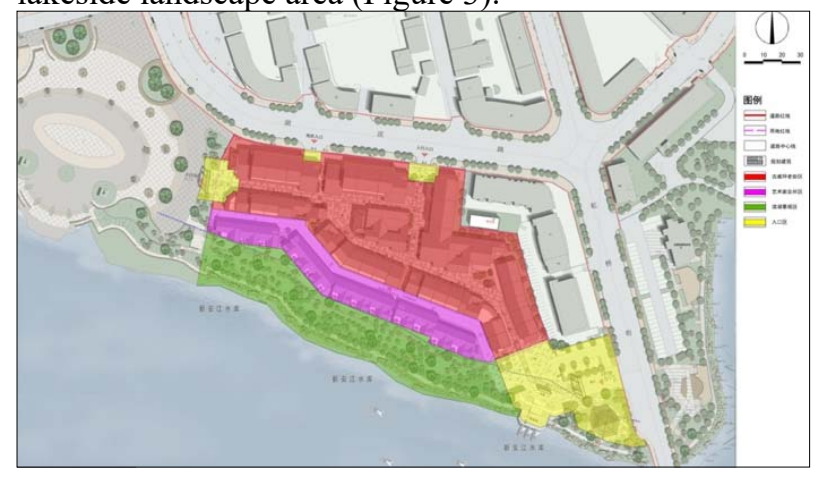

Fig. 3. Functional areas in the project: entrance area (yellow), Weiping old street area (red), artist studios (pink), lakeside landscape area (green). Sources from the author.

\subsection{Entrance area}


According to the surrounding circulation and road traffic conditions, the INK Weiping Tourist Cultural project is divided into three main pedestrian entrances and an underground parking garage entrance, which implements the separation of pedestrians and vehicles. It inherits the open and suitable small-scale traditional block. Memorial arches and squares as symbols marking Huizhou village's main entrance as significant spatial nodes are designed in detail. For example, the west entrance mainly accepts the pedestrian flow of Weiping Square, and there is a "Ke Jia Shi Cheng" arch in front of the entrance axis (Figure 4), responding to the east-west axis of Weiping Square. At the east entrance, the commercial street buildings retreated, and Huizhou's representative xiulou (a loggialike place in upper floors for Chinese women to do the needlework), jiaolou (corner building, see Figure 5) and arch was set up to strengthen the entrance space. Secondly, the entire Shui Mo Weiping Tourist Cultural Street is compared to a mandarin fish, so the east entrance is set up as an antique port at its original place to create the thriving river transport scene of old Weiping in the past. The stress of the entire project a pagoda named "Wannian Ge" was built at the fisheye position, and the base is the tea garden stone "Tianziji." Thirdly, the zhaobi (spirit screen) and other landscape architecture in traditional Hui-style garden are set up in the front square to strengthen the position of the entrance square. The west entrance mainly draws the pedestrian flow from Hubin Road. Through set-back commercial street buildings and balconies on the exterior walls to strengthen the link between buildings and the entrance space.

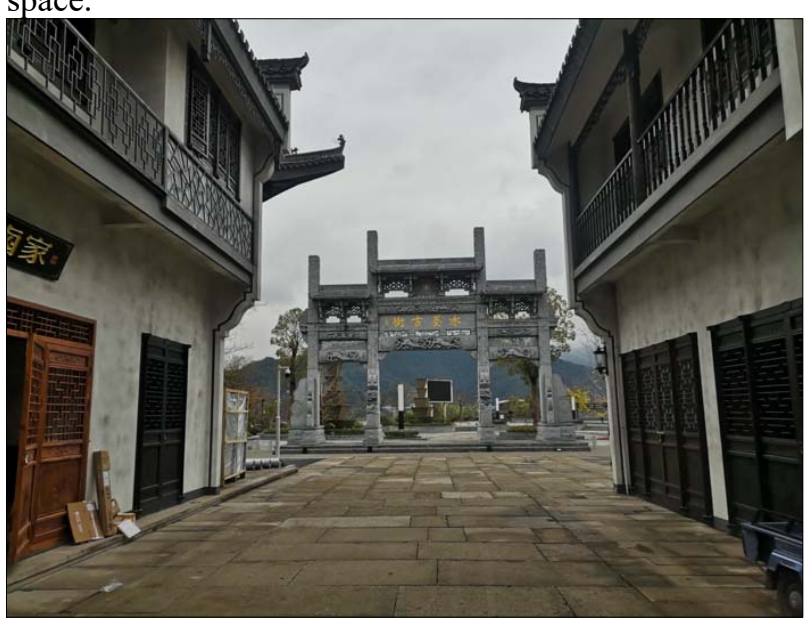

Fig. 4. Entrance arch on the axis formed by Weiping plaza and the street of the project. Sources from the author.

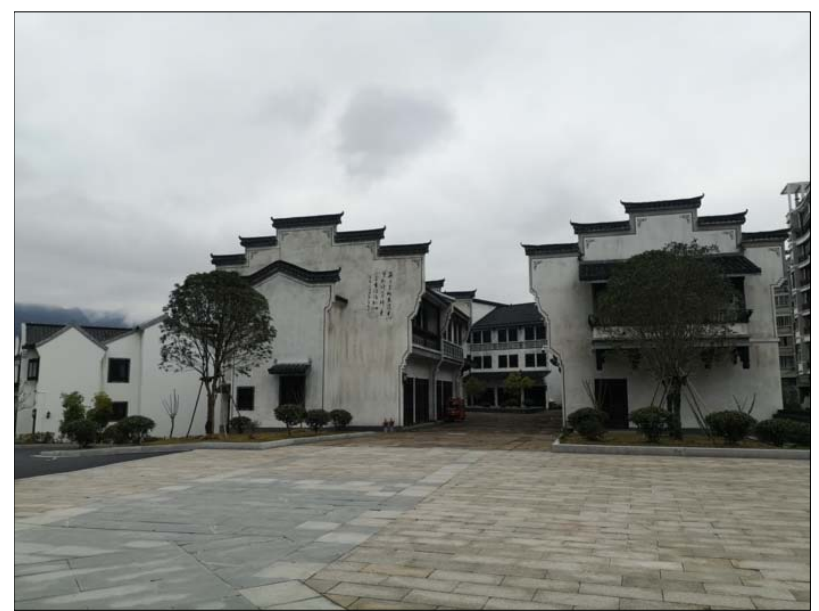

Fig. 5. Corner building marking the entrance at the east plaza. Sources from the author.

\subsection{Weiping old street area}

As the core area of the INK Weiping Tourist Cultural Street, Weiping old Street is divided into categories of the Front Street, the Back Street, the Horizontal Street, and the Lower Street. The buildings are arranged along the above-categorized streets in eight parts: (1) Leisure and cultural area of the waterfront area near the entrance square on the east side. There are open-air tea houses, cafes, bars, art creation rooms, and galleries. Such facilities are proposed to become an area with strong participation by tourists and rich cultural content of sightseeing, shopping, fashion, and leisure. (2) Local product exhibition area exhibits local products from the surrounding villages. Walnuts, tea, dried bamboo shoots, dried fish, seedless persimmon, and other native products and craft, at the same time, attract tourists by selling, introducing the history of unique products, allusions, exquisite display, performance, and personally making and tasting. (3) Traditional craft exhibition area arranges traditional craft workshops for teaching stone carving, brick carving, wood carving, bamboo carving, handicraft manufacture of the product like compasses, bamboo chimneys, and other small things. (4) Medical and health care area promotes Weiping Chinese medicine processing that has long been famous. (5) Particular food display area combines the existing Weiping annual fresh fish barbecue event. Exhibiting Weiping outstanding food such as hot sauce, dates, winter melon candy, peanut candy, moon cake, snow cake, etc. Allowing visitors to taste and participate in activities. (6) Museum of folk houses, celebrities, and specialties houses three reconstructed houses in Weiping area. Architectural models, measured drawings, large building samples, interior furniture, architectural components are displayed. (7) Set up some distinctive hotels along the lake or inside the courtyard building. (8) According to the religion, education, and culture of the old Weiping area, set up performance stage, academy, memorial hall, etc. Finally, in the Weiping Old Street area, some traditional shops are retained and restored according to the above functional areas, for examples, one hall, and one storehouse; pastry workshops, bucket rot workshops, soy sauce workshops, 
shoe shops, clothing shops, tea shops; rice shops, hotels, ceramic shops, wooden shops, iron shops, bamboo shops, medicine shops, gold and silver shops.

\subsection{Artist studios and lakeside landscape area}

INK Weiping Tourist Culture Street draws on the model of Beijing Songzhuang, Guanlan Printmaking Village, and Beijing 798 District, attracting 13 domestic art masters to settle in the 13 artists' studios are located in the project (Figure 6 and Figure 7). The belt-shaped areas along the river are all facing southeast. As studios for meeting between well-known domestic and foreign companies and artists, it provides a platform and opportunity for cultural exchanges and artistic creation. Lakeside landscape area is the Xin'an River waterfront greening area, featuring green land and tree planting. It provides a place where residents can walk and play, combining the natural landscape with Huizhou's cultural landscape.

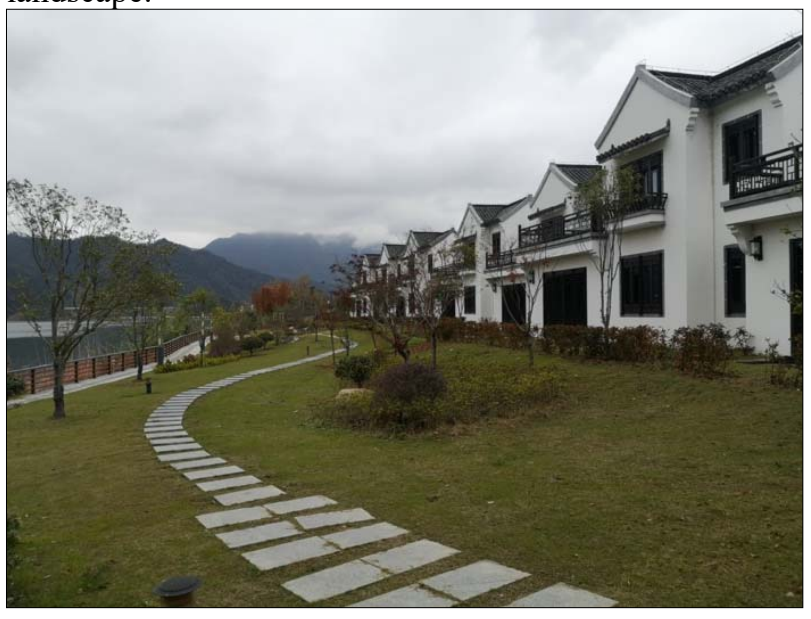

Fig. 6. Artists' studios and lakeside landscape area. Sources from the author.

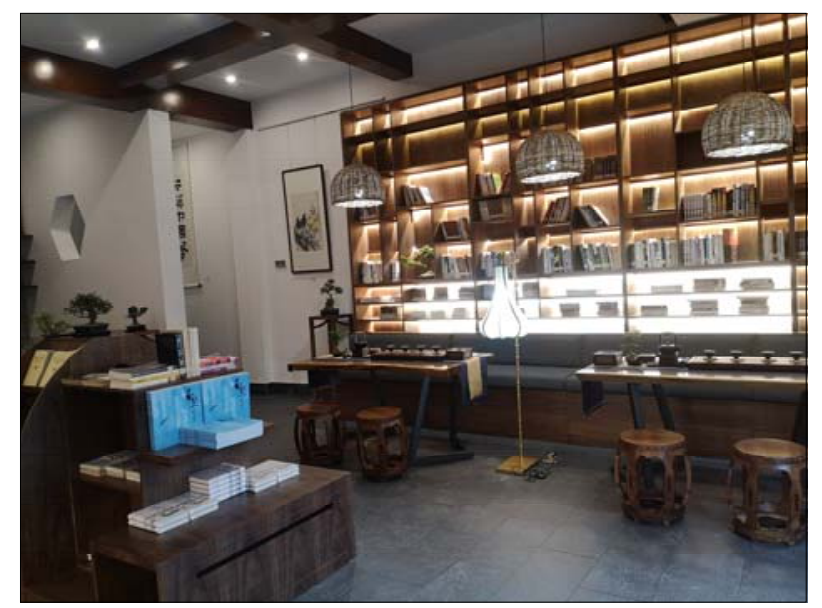

Fig. 7. Interior of Artist' studio. Sources from the author.

\section{Analysis of building design}

\subsection{Building plan}

As an essential carrier for inheriting Hui culture in Old Weiping, residential house design is set up based on the traditional shop mode in front and residence at the rear. The architectural scale and living facilities are adjusted and improved according to the modern lifestyle. The details adopt standard Huizhou architectural features such as window lattices, queti (bracket support), mei ren'kao (seating around the loggia), wood carvings, and stone carvings as decorations, installed with antique furniture. The building design plan can be divided or combined according to function through convenient and flexible dividing walls. The architectural plan of the artist club area adopts a modern architectural plan. The first floor is designed for reception and exhibition, and the second floor is for artists' rest and independent working studio. Simultaneously, a large area of terraces is set along the lake to conform to the contour of the terrain along the lake. It is an extended area convenient for artists to carry out various creative events concerning their studios.

\subsection{Building façade}

Hui-style architecture is an essential part of Weiping's regional environment, and it is the material carrier of Huizhou culture. The "white wall, grey tile, and horse head wall" constitutes the aesthetic theme of ancient Huistyle architecture. The project's architectural form and facade design are based on the inheritance of Hui-style architectural aesthetics in old Weiping Town. In order to echo the modern street facade of Hubin Road, the building facade adopts an improved form of traditional Hui-style commercial storefronts with two or three floors. The facade adopts a three-stage treatment method. The lower part is from the ground to the advertising plaque, and the store number in the first floor, from the lower edge of the balcony railing to the cornice is the middle part; and from the cornice to the roof ridge is the upper part. The lower part is as much open as possible to the street, and structural columns are set to the inner side of the exterior walls.

The door lintel is made of $30-40 \mathrm{~cm}$ beams. The beam to the second-floor protruding part is connected by que ti and xuan (small landscape architecture for beautiful sceneries) components. The store plaque hangs on the protruding middle part below the floor railing. The middle protruding part adopts the method of creating voids to hide the modern air-conditioning behind louvers. The upper part from the cornice to the roof ridge uses small grey tiles, ending with dripping and hooks. Storefronts, on the one hand, are designed based on the traditional standard in detail. On the other hand, modern elements are applied to the building part like doors and windows and facade to meet contemporary business requirements. Horse headwalls on both sides gradually protrude according to the raising curvature of eaves and forming a varied and lively facade outline. The façade of the artist club area mainly draws on the traditional houses of Weiping; it adds modern architectural language such as large-area glass windows on the ground floor and an 
open terrace on the second floor to better display the internal creative activities in art production.

\subsection{Spatial design in architecture}

Spatial design in architecture continues and inherits the characteristics of Huizhou villages' external space. It underlines linear street space, converged node space (such as junctional block space), squares, etc (Figure 8). For street space, the facades of the storefronts in the blocks vary and show different expressions. Shops, houses, and theatres are laid out in a staggered arrangement. The spatial opening and closing, the width, the spatial form is always changing and dynamic. The primary node spaces include the east and west squares, the performance stage, the enlarged area inside the block, pagoda, etc. They are the highlights of the project and attractions for the users (Figure 9).

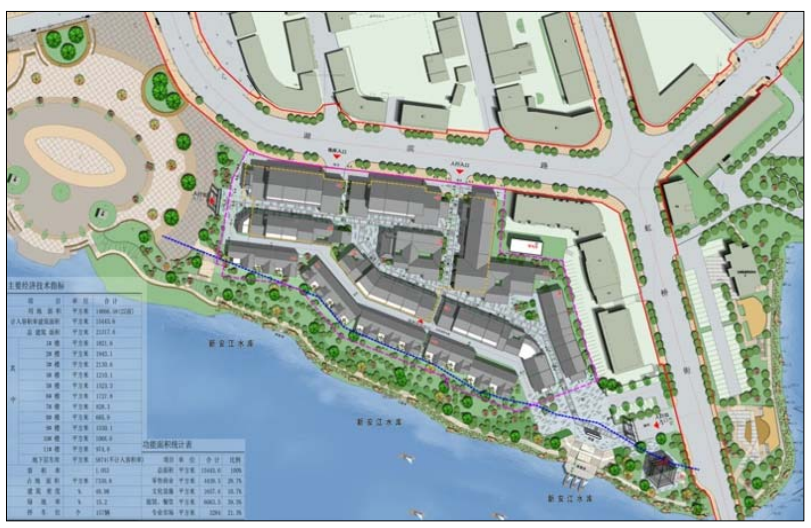

Fig. 8. The master plan of the project. Sources from the author.

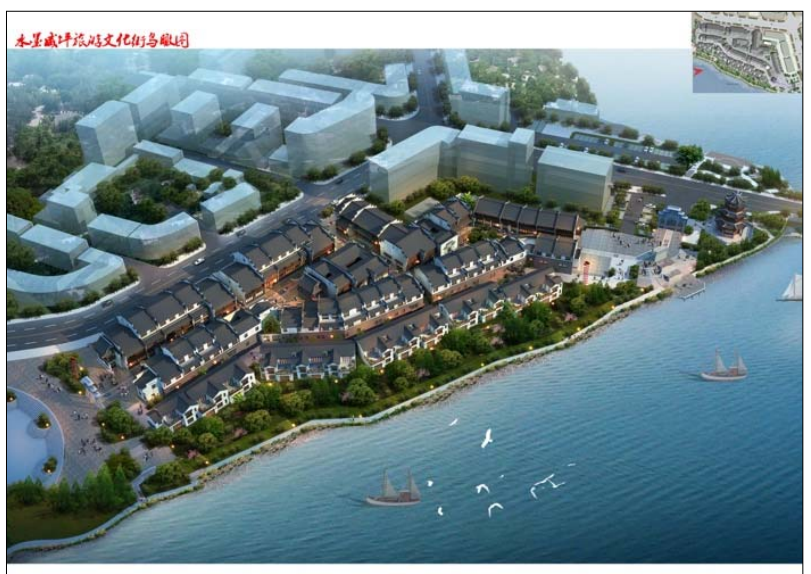

Fig. 9. Aerial view of the project. Sources from the author.

\section{Discussion and conclusion}

In the project's design process, the reference and inheritance of Huizhou culture from large to small scales are gradually expanded. First, it is the consideration of the Chinese Fengshui or geomantic omen for the layout of the buildings in the Huizhou settlement, such as the back of the mountain and the water. The east square is the fisheye, and the west square is the fishtail, abstracting the triangular site into the image of "fish" in the project. Besides, during the construction of the site, the project is integrated into the surrounding urban space through urban design. For example, the East Square adjacent to Hongqiao street is the entrance of the ancient building complex, and it is also an essential node for guiding people to the waterfront space where old water port located and lakeside landscape area with collective memory left on the site. The West Plaza is connected to the city plaza-Weiping Plaza. It is connected with the ancient stage in the center of the building complex in the line of sight, creating another highly accessible urban space in the site. The project actively creates outdoor space in the site, transforms the traffic space into a suitable street space in the traditional Huizhou area, and connects the above-mentioned public spaces to improve the project's overall permeability and mobility. In addition to the traditional interpretation of architectural space, architectural elements such as paifang (entrance arch), zhaobi (entrance walls), matou qiang (horse headwalls), grey tiled sloping roofs, etc. have all become symbols in the representation of Huizhou culture embedded within. The project concept does not stop at the construction of the physical environment but also considers how to better integrate the later use with the building by considering its programs. The atmosphere of the traditional streets is inseparable from the traditional commercial streetscape. The handicrafts, the display of specialty food workshops, and the performances of singing troupes contribute to the inheritance of Huizhou culture together with the architectural design as a backdrop.

In the project's design process, the author also encountered unsatisfactory and unexpected issues that need to be improved in future practice. The shoppers did not organize as a community to standardize the design. As a result, shops in the project did not have a good uniform style in creating the signs. This issue resulted in a strong contrast between the white wall's Hui-style and the grey tiles and the modern signs and red banners (Figure 10).

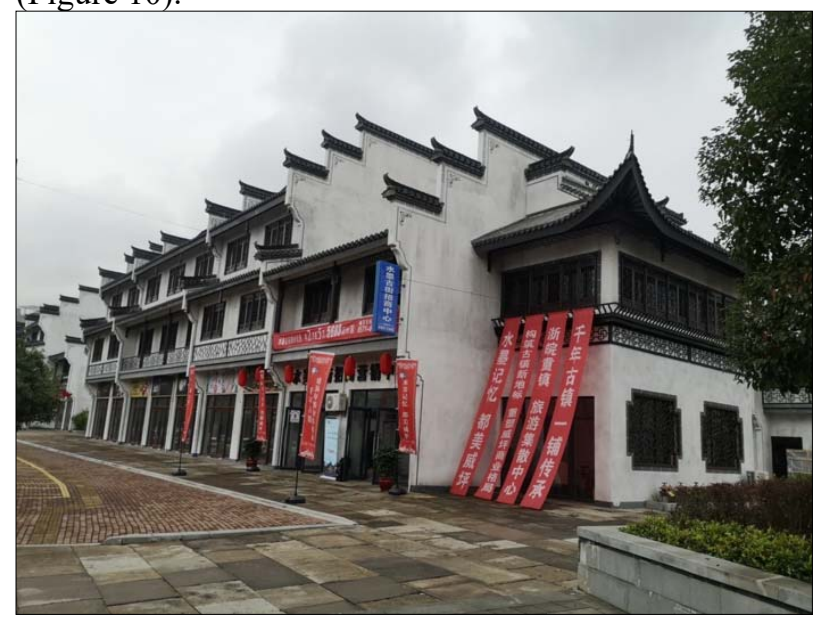

Fig. 10. Signboards and banners contrast with traditional Huistyle architecture. Sources from the author.

In addition, the details of the design were not well grasped by the constructors who usually practice in the 
construction of modern architecture in the city area. It results in the low level of completion of the building, and the artistic conception of the design was not fully expressed. It can be seen from this project that the integration of design and construction in the traditional Huizhou architecture has shifted to the division of design and construction in modern architectural practice and cause further issues. The traditional architectural skills play a decisive role in realizing and whether the original design concepts can be fully expressed. In future design and planning, it is also necessary to consider integrating store signs and interior furniture into the building's overall design. The culture and inheritance in Huizhou through architectural design still needs to be continuously improved in future practice.

\section{Acknowledgements}

This paper has been supported by the following fund projects. MOE (Ministry of Education of the People's Republic of China) Youth Fund Project of Humanities and Social Sciences (Project No.18YJC850002). Bidding Project of Key Research Base of Humanities and Social Sciences in Colleges and Universities of Anhui Province (Project No. SK2015A170). "10303 plan of Huizhou research talents training" project of Huangshan Social Science Federation.

\section{References}

1. Huangshan City Statistics Bureau, Huangshan City Statistical Yearbook, 97(Huangshan, Huangshan City Statistics Bureau, 2020)

2. Huangshan City Cultural Committee, Decision 9, 1012(2012)

3. X. Yin et al., Anhui Daily 10, (2017)

4. Y. Yang, W. Huang, The Science Educaton Article Collects, 12, 205-206(2013)

5. X. Guan, X.Y, Wang, J. Zheng, Journal of Hefei University of Technology, 27(5), 98-102(2013)

6. J.H. Liao, Reform 290(4),130-139(2018)

7. Z.M, Peng, Anhui Jianzhu University master degree thesis, (2017)

8. D.Q, Shan, X.M, Li, China Engineering \& Consulting, 03, 30-33(2008)

9. W. Nie, Anhui Architecture 176(1),28-30(2011)

10. J. LI, Market Weekly, 4, 106-108(2016)

11. X. Kong, F.Y, Zhuo, C.S. Miao, Tropical Geography 36(2), 216-224(2016)

12. Z.F. Huang, R. Huang, Geographical Research 37(2), 233-249(2018)

13. C.N. Schulz, Genius Loci: Towards a phenomenology of architecture, (New York, Rizzoli, 1979)

14. A. Rossi, The architecture of the city (Cambridge, The MIT Press, 1984) 